\title{
Research on Inventory Pledge Financing Pledge Decision under Internet of Things Technology
}

\section{Xiangxiang Zhang* Gengjun Gao}

Institute of Logistics Science and Engineering, Shanghai Maritime University, Shanghai, 201306, China

\begin{tabular}{|c|c|}
\hline ARTICLE INFO & ABSTRACT \\
\hline Article history & \multirow{16}{*}{$\begin{array}{l}\text { Inventory pledge financing not only solves the financing difficulties of } \\
\text { small and medium-sized enterprises, but also opens up business chan- } \\
\text { nels for banks. Under the random market demand, this article studies the } \\
\text { pledge decision-making of perishable pledges in the inventory pledge } \\
\text { business, On the basis of considering the supervision of the Internet of } \\
\text { Things technology to reduce the loss rate of quality goods, a decision } \\
\text { model of the pledge rate of the bank is constructed in the case of not } \\
\text { adopting the Internet of things technology and adopting the Internet of } \\
\text { things technology. The pledge rate decision-making model in the two } \\
\text { technical situations aims at maximizing the profit at the end of the pledge } \\
\text { period. The factors in the model such as the pledge rate, end-of-period } \\
\text { income, and IoT technology coverage rate are analyzed respectively, and } \\
\text { finally the decision-making process is verified through calculation ex- } \\
\text { amples. Studies have shown that, when Internet of Things technology is } \\
\text { not adopted, the income of bank pledge business first increases and then } \\
\text { decreases with the growth of pledge rate. After the adoption of Internet of } \\
\text { Things technology, the income of Banks is inversely proportional to the } \\
\text { coverage rate of Internet of Things technology. However, within a certain } \\
\text { coverage range, Banks can obtain greater income by using Internet of } \\
\text { Things technology to supervise pledges. }\end{array}$} \\
\hline Received: 24 September 2020 & \\
\hline Revised: 30 September 2020 & \\
\hline Accepted: 9 October 2020 & \\
\hline Published Online: 16 October 2020 & \\
\hline Keywords: & \\
\hline SMFs & \\
\hline SMIES & \\
\hline Inventory pledge financing & \\
\hline Pledge rate & \\
\hline Internet of Things technology & \\
\hline & \\
\hline & \\
\hline & \\
\hline & \\
\hline & \\
\hline
\end{tabular}

\section{Introduction}

$\mathrm{S}$ mall and medium-sized enterprises are an important part of the modern national economy and have a broad social and economic foundation. Therefore, the number of such enterprises in china has an absolute advantage. By the end of 2019, the total number of small and medium-sized enterprises nationwide in china was $15,278,400$. Among them, there are $11,698,700$ small and medium enterprises, accounting for $76.57 \%$ of the number of enterprises. After 44,362,900 individual businesses were included in the statistics, the proportion of small and medium-sized enterprises reached $94.15 \%$. Small and medium-sized enterprises are the basic force that promotes employment, improves people's livelihood, stabilizes society, develops the economy, and promotes innovation. They are the largest and most dynamic group of enterprises that constitute the main body of the market economy. The development status of SMEs is related to the adjustment of China's economic and social

*Corresponding Author:

Xiangxiang Zhang,

Shanghai Maritime University, Shanghai, 201306, China;

E-mail:15726204607@163.com. 
structure and the transformation of development mode, the promotion of employment and social stability, and the technological innovation and transformation and upgrading ${ }^{[1]}$. Although small and medium-sized enterprises have made remarkable achievements, the narrow financing channels, small scale, weak strength and poor ability to withstand risks have caused financial institutions to face large risks in loans to small and medium-sized enterprises, making small and medium-sized enterprises face financing difficulties, slow financing, and high cost. In today's fiercely competitive environment, in order to better serve downstream customers, small and medium-sized enterprises often have a large backlog of inventories, occupy a large amount of capital, and slow capital turnover, which affects production and operation. The 2015 "13th Five-Year Plan" proposes to implement financial system reforms and improve the financial market system to promote inclusive finance to promote the recovery of the real economy. As a typical form of logistics finance, the inventory pledge financing business has become an effective way to solve the financing dilemma. Inventory pledge financing means that the borrower enterprise uses its movable property as a guarantee to pledge to the fund provider such as the bank, and at the same time, transfer the pledge to The business activities of a logistics company (intermediary) that has the legal qualification for safekeeping of movable properties to obtain loans ${ }^{[2]}$. Compared with the traditional loan business, the inventory pledge business is to pledge excess inventory to financial institutions, paying more attention to the pledge, rather than just focusing on the size and capital of the enterprise. This business can firstly enable SMEs to get rid of financing difficulties caused by insufficient credit ratings and guarantees, and use inventory to solve funding difficulties. Secondly, third-party logistics companies can participate in obtaining more customer resources and consulting and regulatory business benefits. Financial institutions have expanded their business scope. Get a fat profit ${ }^{[3]}$.

In this paper, we will establish two pledge rate decision-making models under the traditional supervision of banks and the use of Internet of Things technology to analyze the decision-making and optimal benefits of the loss of pledged materials. The structure of other parts of this paper are as follows:The section 2 is a literature review of inventory Staking and Internet of Things, the section 3 is the problem description and symbol explanation, the model establishment are stated in Section 4, Section 5 validates the model with an example. Finally, a conclusion is provided in Section 6.

\section{Literature References}

The inventory pledge business meets the needs of the economy and society and has developed rapidly in the early stages of development. It has also attracted a large number of domestic and foreign scholars to study the business, including research on the inventory pledge business model, pledge rate setting, and loss rate reduction. For example, Poe explained an important model in logistics finance, namely, asset-based financing. It is believed that the collateral that must be considered for pledge financing of inventory and accounts receivable, enterprises at all levels should be considered for financing business ${ }^{[4]}$. Wright analyzed the value of inventory in logistics finance, and believed that it was related to market fluctuations and various factors of financing companies, and proposed that the participation of third-party logistics companies can bring new protection to financing business ${ }^{[5]}$.Yixue Li and others studied the development process of inventory pledge business at home and abroad, analyzed the environmental factors and legal system factors of the development of inventory pledge business from the perspective of logistics and finance, and put forward corresponding countermeasures for the development of inventory pledge business in china ${ }^{[6]}$. In terms of pledge rate, Cossin et al. relaxed the assumption of the endogenous probability of default, and obtained a pledge rate consistent with the bank's risk tolerance based on the exogenous probability of default ${ }^{[7]}$; On this basis, Yixue Li continued to use simplified thinking, and comprehensively considered the influence of bank risk preferences, price fluctuations, and mark-to-market cycles, established a decision model for the pledge rate of inventory financing business ${ }^{[8]}$. Hui Yu considers the endogenous default and uncertain demand to establish a single-period newsboy model to study the decision-making problem of pledge rate ${ }^{[9]}$. Qinhong Zhang and others analyzed the pledge rate decision-making problem when the risk attitude of decision-making subjects is different under the random condition of the pledge market demand $^{[10]}$; In terms of studying the loss of pledges, Yan Shi and others established a production inventory model of perishable items under the inventory pledge financing strategy, taking into account the loss of pledges ${ }^{[11]}$; Under the random fluctuations of inventory demand, Yongming Pan and others consider the impact of inventory loss on decision-making during the inventory pledge process, the bank's lower risk control and the enterprise's ability to repay loans to establish a bank profit maximization model ${ }^{[12]}$; Yunfeng Zhang and others studied inventory pledge financing under the consideration of the loss of 
pledges, derived the influence of incentive levels on the level of supervision efforts and expected returns under the three modes of entrusted supervision, joint operation and unified credit, and further studied the investment needs of SMEs after financing Inventory pledge decision $\operatorname{model}^{[13-14]}$

To sum up, the research results on the inventory pledge financing business are quite rich, but in terms of the loss of pledged goods, the inevitable loss of pledged inventory will affect the expected income of all parties involved in the business. There are documents that mostly use financial institutions to incentivize third-party logistics companies, thereby reducing the pledge rate of pledged inventory.However, with the rapid development of the information technology industry today, the rapid development of Internet of Things technology has provided new solutions for improving the level of supervision of the inventory pledge business and reducing the inventory loss rate. For example, Yongzhang Gong combines supply chain finance with the Internet of Things technology, and monitors all links in the pledge supervision process through the Internet of Things to ensure the smooth progress of the inventory pledge business ${ }^{[15]}$; Lingyan Jiang and others used the Internet of Things technology to prevent repeated pledge risks, and established a model to analyze the changes in the income of banks and third-party logistics companies before and after the adoption of the Internet of Things technology ${ }^{[16]}$. However, the literature in this area has not yet involved the use of Internet of Things technology to improve the level of supervision to reduce the loss of pledged goods. In view of this, this article focuses on the large and easily lossy pledge inventory, and considers using Internet of Things technology to improve the supervision level of third-party logistics companies to promote The reduction of the loss rate, based on this, discusses the decision-making optimization problem of the pledge rate in the inventory pledge financing business.

\section{Problem Definition}

At the beginning of the pledge period, the financing company submits an inventory pledge financing application to the bank, and delivers the inventory to the third-party logistics company. The bank evaluates the pledge rate and sets the pledge rate to the company to lend money. Third-party logistics companies supervise the pledges, but due to the information asymmetry between the supervising companies and the banks, the supervising companies may have a high rate of loss of pledges due to their own negligence and improper storage during the supervision process, resulting in the loss of bank pledges. Pledge supervision risks arise. During the pledge process, the bank uses the IoT pledge supervision platform to monitor the dynamics of pledges in an all-round and full process, realizing real-time supervision of the position, status and ownership of the pledges. In order to improve the level of supervision of third-party logistics companies, SMEs at the end of the pledge period choose whether to repay the loan according to their own wishes and market demand. If the company chooses to default, the bank will deal with the inventory and obtain benefits. (see Figure.1)

In order to better study the problem, we need to assume:

(1) Banks and small and medium-sized enterprises have symmetrical information. At the end of the pledge period, banks and financing companies have the same ability to handle pledged inventory.

(2) The pledged inventory will be lost during the pledge process; banks and third-party logistics companies have asymmetric information about the supervision of pledges.

(3) The market demand fluctuates randomly and obeys a certain distribution, and the unit price of the pledged inventory is stable during the pledge period.

(4) At the same time, consider the endogenous default rate and exogenous default rate of the financing enterprise, and default behavior occurs when both occur simultaneously.

(5) The supervision cost of logistics companies consists of two parts: the labor supervision cost of third-party companies that do not use the Internet of Things technology and the input cost of the supervision of the Internet of Things technology. The higher the coverage, the more the sensing devices, detection devices, tags, etc. Increase in the cost of IoT supervision.

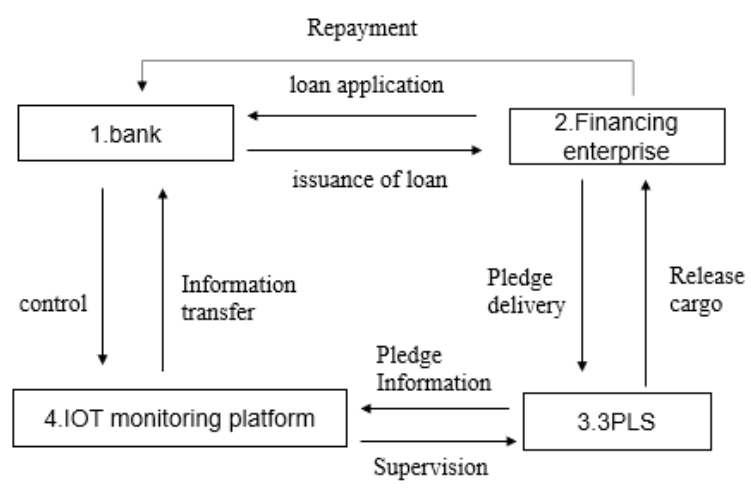

Figure 1. Inventory pledge financing flow chart

\section{Model}

In this section, we will establish a pledge rate model for banks with and without IOT technology for analysis 
and comparison. First give a summary of the symbols to be used in the model (See Table 1)

Table 1. Meaning of model index/parameters/decision variable

\begin{tabular}{|c|c|c|c|}
\hline Symbol & Description & Symbol & Description \\
\hline$q_{0}$ & $\begin{array}{c}\text { Quantity of pledge at the } \\
\text { beginning of pledge period }\end{array}$ & $u$ & $\begin{array}{l}\text { The collateral market } \\
\text { demand at the end of the } \\
\text { period, the distribution } \\
\text { function is } F(\mathrm{x}) \text {, The pro- } \\
\text { bability density function } \\
\text { is } f(\mathrm{x}), \mathrm{u} \geq 0\end{array}$ \\
\hline$P$ & $\begin{array}{c}\text { The unit price of the } \\
\text { pledge, the price remains } \\
\text { unchanged within a shorter } \\
\text { pledge period } p>0\end{array}$ & $g$ & $\begin{array}{l}\text { End-of-period processing } \\
\text { price of remaining inven- } \\
\text { tory } 0<\mathrm{g}<\mathrm{p}\end{array}$ \\
\hline$R$ & $\begin{array}{c}\text { Financing company pledge } \\
\text { loan interest rate }\end{array}$ & $Q$ & $\begin{array}{l}\text { Exogenous default rate of } \\
\text { financing companies }\end{array}$ \\
\hline$\omega$ & $\begin{array}{c}\text { Pledge rate (the ratio of } \\
\text { loan amount to pledged } \\
\text { inventory value), } 0 \leq \omega \leq 1\end{array}$ & $r$ & $\begin{array}{l}\text { Bank loan cost interest } \\
\text { rate }\end{array}$ \\
\hline$\pi$ & $\begin{array}{l}\text { Bank's profit at the end of } \\
\text { the pledge business }\end{array}$ & $a$ & $\begin{array}{l}\text { Inventory depletion rate } \\
\text { during pledge period, } \\
\text { including natural depleti- } \\
\text { on rate, supervision and } \\
\text { storage negligence loss } \\
0<\alpha\end{array}$ \\
\hline$a_{0}$ & $\begin{array}{c}\text { Initial attrition rate, that is, } \\
\text { the attrition rate when the } \\
\text { bank does not use the IoT } \\
\text { platform }\end{array}$ & $i$ & $\begin{array}{l}\text { Pledge inventory loss } \\
\text { improvement factor, } \mathrm{i}>0\end{array}$ \\
\hline$\theta$ & $\begin{array}{c}\text { Coverage factor for banks } \\
\text { using IoT technology } \\
0<\theta<1\end{array}$ & $T$ & $\begin{array}{l}\text { The pledge cycle of } \\
\text { pledge business }\end{array}$ \\
\hline$t$ & $\begin{array}{l}\text { A certain moment du- } \\
\text { ring the pledge busi- } \\
\text { ness, } 0 \leq \mathrm{t} \leq T\end{array}$ & $Z(t)$ & $\begin{array}{l}\text { Pledge inventory invento- } \\
\text { ry at time t }\end{array}$ \\
\hline $\mathrm{c}_{0}$ & $\begin{array}{c}\text { Regulatory costs when not } \\
\text { using IOT technology }\end{array}$ & $\mathrm{C}(\theta)$ & Bank supervision costs \\
\hline$l$ & $\begin{array}{l}\text { Maximum loan loss } \\
\text { that the bank can af- } \\
\text { ford, } 0<l<1\end{array}$ & $\eta$ & $\begin{array}{l}\text { Maximum risk tolerance } \\
\text { that the bank is willing to } \\
\text { accept, } 0<\eta<0\end{array}$ \\
\hline
\end{tabular}

\subsection{Scenarios Not Using IOT technology}

\subsubsection{Objective Function}

When the bank does not use the Internet of Things technology, the inventory enters the pledge warehouse of the third-party logistics company, and the bank sets a fixed supervision fee for the third-party logistics company. Considering the loss of inventory, the remaining inventory and time meet the conditions ${ }^{[12-13]}$.

$$
\left\{\begin{array}{c}
\frac{\mathrm{d} Z(\mathrm{t})}{\mathrm{dt}}=-\alpha_{0} Z(\mathrm{t}) \\
Z(0)=q_{0}
\end{array}\right.
$$

From formula (1), the formula for the remaining amount of pledged inventory is

$Z(\mathrm{t})=q_{0} \mathrm{e}^{-\alpha_{0} \mathrm{t}}$

The loan of the financing enterprise at the beginning of the pledge business period is $\omega \mathrm{q}_{0} \mathrm{p}$, During the pledge period, the price of the pledged property is stable, and at the end of the pledge period, the Repayment of principal and interest is as follows $\omega \mathrm{q}_{\mathrm{o}} \mathrm{p}(1+\mathrm{RT})$, Considering that when the pledge rate is set from the perspective of the bank, the value obtained by the financing enterprise from normal sales of the pledge should not be lower than the sum of the loan principal and interest, therefore, the remaining value of the pledge at the end of the pledge period is $p u+g(Z(t)-u)$, There will be three situations at the end of the pledge period:

(1) $\mathrm{pu}+\mathrm{g}(\mathrm{Z}(\mathrm{t})-\mathrm{u}) \geq \omega \mathrm{q}_{0} \mathrm{p}(1+\mathrm{RT})$, The financing company returns the principal and interest of the loan, and the bank informs the 3PL company to release all pledges to the financing company;

(2) $\mathrm{pu}+\mathrm{g}(\mathrm{Z}(\mathrm{t})-\mathrm{u})<\omega \mathrm{q}_{0} \mathrm{p}(1+\mathrm{RT})$, The financing company does not default with the probability of, and the financing company returns the principal and interest of the loan;

(3) $\mathrm{pu}+\mathrm{g}(\mathrm{Z}(\mathrm{t})-\mathrm{u})<\omega \mathrm{q}_{0} \mathrm{p}(1+\mathrm{RT})$, The financing company defaults with probability $\mathrm{Q}$, the pledge business ends, and it enters the liquidation process.

From this, it can be concluded that the critical demand $\mathrm{u}_{1}$ for the endogenous default of the pledge business, when $\mathrm{u} \geq \mathrm{u}_{1}$, the financing company does not default, when $\mathbf{u}<\mathrm{u}_{1}$, the financing company may default, $\mathrm{u}_{1}$ can be expressed as follows:

$\mathrm{pu}+\mathrm{g}(\mathrm{Z}(\mathrm{t})-\mathrm{u})=\omega \mathrm{q}_{0} \mathrm{p}(1+\mathrm{RT}) \rightarrow \mathrm{u}_{1}=\frac{\omega \mathrm{q}_{0} \mathrm{p}(1+\mathrm{RT})-\mathrm{gZ}(\mathrm{t})}{\mathrm{p}-\mathrm{g}}$

The expected return function of the bank is

$$
\begin{aligned}
& \pi_{1}=\int_{0}^{\mathrm{u}_{1}}\left(Q\left\{[\mathrm{pu}+g(\mathrm{Z}(\mathrm{t})-\mathrm{u})]-\omega \mathrm{pq}_{0}(1+\mathrm{rT})\right\}+(1-Q) \omega \mathrm{pq}_{0}(R T-\mathrm{r} T)\right) \mathrm{f}(u) d u \\
& +\int_{u_{1}}^{+\infty} \omega \mathrm{pq}_{0}(\mathrm{RT}-\mathrm{rT}) \mathrm{f}(\mathrm{u}) \mathrm{du}-\mathrm{c}_{0} \\
& \quad=\mathrm{Q}(\mathrm{p}-\mathrm{g}) \int_{0}^{u_{1}} u \mathrm{f}(u) d u+\mathrm{QF}\left(\mathrm{u}_{1}\right) g \mathrm{Z}(\mathrm{t})-Q \omega \mathrm{pq}_{0}(1+\mathrm{rT}) \mathrm{F}\left(\mathrm{u}_{1}\right)+ \\
& \left(1-\mathrm{QF}\left(\mathrm{u}_{1}\right)\right) \omega \mathrm{pq}_{0}(\mathrm{RT}-\mathrm{rT})-\mathrm{c}_{0}
\end{aligned}
$$

\subsubsection{Model Building}

In terms of constraints, in order for the pledge business to proceed smoothly, the total value of the pledged goods normally sold by the financing enterprise in the pledge business must be no less than the sum of the principal and interest of the pledged loan, so it can be known: 
$\mathrm{p} Z(\mathrm{t}) \geq \omega \mathrm{pq}_{0}(1+\mathrm{RT})$

The bank will adopt the downside risk control strategy, so it can be expressed as:

$$
P\left(\omega \mathrm{pq}_{0}(1+\mathrm{RT})-(\mathrm{pu}+g(\mathrm{Z}(\mathrm{t})-\mathrm{u})) \geq l \omega \mathrm{pq}_{0}\right) \leq \eta
$$

The model can be obtained by combining the above formulas as follows:

$$
\begin{aligned}
& \max \pi_{1}=\mathrm{Q}(\mathrm{p}-\mathrm{g}) \int_{0}^{\mathrm{u}_{1}} u \mathrm{f}(u) d u+\mathrm{QF}\left(\mathrm{u}_{1}\right) g \mathrm{Z}(\mathrm{t})-Q \omega \mathrm{pq}_{0}(1+\mathrm{rT}) \mathrm{F}\left(\mathrm{u}_{1}\right) \\
& +\left(1-\mathrm{QF}\left(\mathrm{u}_{1}\right)\right) \omega \mathrm{pq}_{0}(\mathrm{RT}-\mathrm{rT})-\mathrm{c}_{0} \\
& \text { s.t. }\left\{\begin{array}{c}
\mathrm{p} Z(\mathrm{t}) \geq \omega \mathrm{pq}_{0}(1+\mathrm{RT}) \\
P\left(\omega \mathrm{pq}_{0}(1+\mathrm{RT})-(\mathrm{pu}+g(\mathrm{Z}(\mathrm{t})-\mathrm{u})) \geq l \omega \mathrm{pq}_{0}\right) \leq \eta \\
0 \leq \omega \leq 1
\end{array}\right.
\end{aligned}
$$

\subsection{Scenarios Using IOT Technology}

\subsubsection{Objective Function}

In traditional inventory pledge financing, inventory supervision is dominated by manual supervision led by third-party logistics companies, and banks pay fixed supervision fees to third-party logistics companies, but this kind of supervision often results in low-level efforts of third-party logistics companies. Causes high loss. Therefore, in this module, the bank adopts the Internet of Things technology to see the inventory supervision status at the terminal, thereby increasing the effort of third-party logistics companies and reducing the loss rate of pledges.

First, set the loss improvement function under the Internet of Things technology adopted by the bank. When the bank adopts Internet of Things technology supervision, the pledge inventory loss rate changes from the initial A to D. This function is two-order continuous and differentiable, and has the following properties:

(1) $\alpha^{\prime}(\theta \leq 0$, Indicates that the loss rate decreases as the coverage of the Internet of Things increases;

(2) $\alpha^{\top}(\theta \geq 0$, The marginal cost of IoT coverage to reduce the loss rate is increasing;

(3) $\alpha\left(0=\alpha_{0}\right.$, Banks do not use Internet of Things technology, and the pledge inventory loss rate is still $\alpha_{0}$.

Therefore, the loss improvement function under the Internet of Things technology can be set, where $\mathrm{i}$ is the loss rate improvement factor, $\mathrm{i}>0$.

$$
\alpha(\theta)=\alpha_{0} \mathrm{e}^{-\mathrm{i} \theta}
$$

Correspondingly, while increasing the technology coverage of the Internet of Things, banks must also invest in corresponding sensing devices, tag devices and other costs in addition to the fixed third-party logistics enterprise supervision fees. Therefore, the supervision cost of a bank consists of two parts, the labor supervision cost of third-party companies that do not use the Internet of Things technology and the input cost of supervision using the Internet of Things technology, where $\mathrm{c}_{0}$ represents the supervision cost of not using the Internet of Things technology, $b$ is the adjustment factor including the initial pledge inventory quantity, $C^{\prime}(\theta)<0, C^{\prime \prime}(\theta)>0$, The specific form is as follows:

$C(\theta)=\mathrm{c}_{0}+\mathrm{bln}(1-\theta)$

$C(0)=\mathrm{c}_{0}$ Indicates that when the coverage is 0 , the bank pays the labor supervision cost of the third-party logistics company, $C(1)=+\infty$ It means that the Internet of Things technology is completely covered, and the cost that banks need to pay is infinite.

In summary, the expected return objective function of banks using IoT technology is as follows:

$$
\begin{aligned}
& \pi_{2}=\mathrm{Q}(\mathrm{p}-\mathrm{g}) \int_{0}^{\omega \mathrm{q}_{0} \mathrm{p}(1+\mathrm{RT})-\mathrm{gZ}(\mathrm{t})} \frac{\mathrm{p}-\mathrm{g}}{\mathrm{f}}(u) d u+\mathrm{QF}\left(\mathrm{u}_{1}\right) g \mathrm{Z}(\mathrm{t})-Q \omega \mathrm{pq}_{0}(1+\mathrm{rT}) \mathrm{F}\left(\mathrm{u}_{1}\right) \\
& +\left(1-\mathrm{QF}\left(\mathrm{u}_{1}\right)\right) \omega \mathrm{pq}_{0}(\mathrm{RT}-\mathrm{rT})-C(\theta)
\end{aligned}
$$

\subsubsection{Model Building}

The constraint conditions are the same as scenario 1, and The bank adopts the pledge rate decision model under the Internet of Things technology as:

$$
\begin{aligned}
& \max \pi_{1}=\mathrm{Q}(\mathrm{p}-\mathrm{g}) \int_{0}^{\frac{\omega \mathrm{q}_{0} \mathrm{p}(1+\mathrm{RT})-\mathrm{gZ}(\mathrm{t})}{\mathrm{p}-\mathrm{g}}} u \mathrm{f}(u) d u+\mathrm{QF}\left(\mathrm{u}_{1}\right) g \mathrm{Z}(\mathrm{t})-Q \omega \mathrm{pq}_{0}(1+\mathrm{rT}) \mathrm{F}\left(\mathrm{u}_{1}\right) \\
& +\left(1-\mathrm{QF}\left(\mathrm{u}_{1}\right)\right) \omega \mathrm{pq}_{0}(\mathrm{RT}-\mathrm{rT})-C(\theta) \\
& \text { s.t. }\left\{\begin{array}{c}
\mathrm{p} Z(\mathrm{t}) \geq \omega \mathrm{pq}_{0}(1+\mathrm{RT}) \\
\alpha=\alpha_{0} \mathrm{e}^{-\mathrm{i} \theta} \\
Z(\mathrm{t})=q_{0} \mathrm{e}^{-\alpha \mathrm{t}} \\
C(\theta)=\mathrm{c}_{0}+\mathrm{bln}(1-\theta) \\
P\left(\omega \mathrm{pq}_{0}(1+\mathrm{RT})-(\mathrm{pu}+g(\mathrm{Z}(\mathrm{t})-\mathrm{u})) \geq l \omega \mathrm{pq}_{0}\right) \leq \eta
\end{array}\right.
\end{aligned}
$$

\section{Case Study and Results}

This section uses numerical simulations and example simulations to discuss the inventory pledge rate decision of banks without and without IoT technology, as well as the comparison and analysis of factors such as attrition rate, bank's best profit, and IoT coverage rate. , In order to provide suggestions and guidance to entities who want to use the Internet of Things technology to improve the level of supervision in practice.

Suppose a company delivers a batch of soybeans to 
a 3PL company designated by a financial institution for supervision and applies for an inventory pledge loan from the bank. The quantity of soybeans is $\mathrm{q} 0=10000$ (hundred catties), and the unit selling price is $\mathrm{p}=120$ (yuan/hundred catties).For salvage value $\mathrm{g}=50$ (yuan/hundred catties), the pledge period is 3 months. The contract stipulates that the bank adopts the entrusted supervision inventory pledge model.During the pledge process, the exogenous default rate of financing enterprises is $\mathrm{Q}=0.6$, the expected capital return rate set by financial institutions is $\mathrm{R}=1.25 \%$ / month, and the capital cost $\mathrm{r}=0.75 \% /$ month. The market demand $u$ of the pledge at the end of the pledge period obeys a normal distribution with a mean value of 9000 and a variance of 2000. Loss improvement factor $\mathrm{i}=20000$, risk index $1=0.1, \eta=0.01 . \alpha=0.02 /$ month, the supervision cost of the Internet of Things $C(\theta)=1000+2000 \ln (1-\theta)$. Through the calculation of the model, determine the pledge rate decision of the bank to maximize profits without using the Internet of Things technology and adopt the Internet of Things technology Under the best quality pledge rate decision, the impact of the Internet of Things technology coverage rate and pledge loss rate on the bank's ending income is analyzed.

First, analyze the constraints in the model, and use matlab2018b to calculate the constraints and get the pledge rate range as $0 \leq \omega \leq 0.701$, In the mathematica software,Substitute the pledge rate range into the objective function under the supervision of the bank not using IOT technology, The trend of available profits is shown in Figure 2

Table 2. transformation of profits when banks do not adopt IOT technology

\begin{tabular}{|c|c|c|c|c|c|}
\hline$\omega$ & 0.557 & 0.603 & 0.648 & 0.673 & 0.701 \\
\hline$\pi_{1}$ & 9070.5 & 9761.5 & 10257.4 & 10363.7 & 10197.6 \\
\hline
\end{tabular}

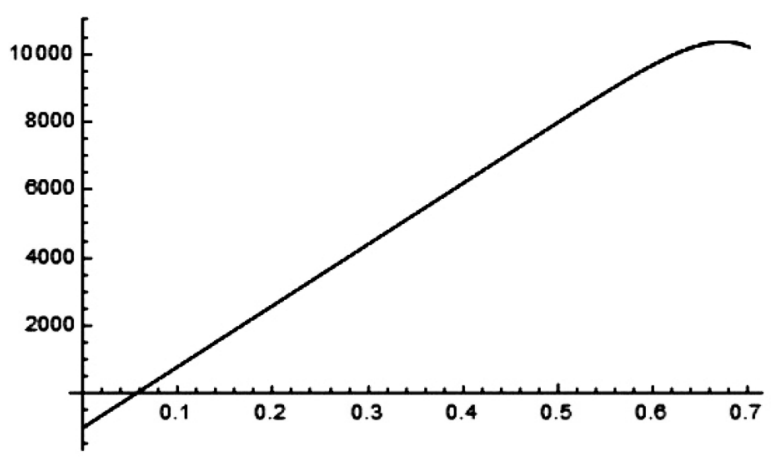

Figure 2. The trend of profit changes under the banks not using IoT technology

In the case of financial institutions that do not adopt the Internet of Things technology supervision, the parti- al simulation results of bank profits with the pledge rate are shown in Table 2. It can be obtained that the highest quality pledge rate is 0.673 without the supervision of the Internet of Things technology, and the bank pledge business is the largest The profit at the end of the period was 10363.7 yuan. In the bank's pledge rate decision, if the pledge rate is $0 \leq \omega \leq 0.061$, Then the bank pledge business is in a state of loss, and the ending profit is less than 0 . Pledge rate is $0.061 \leq \omega \leq 0.673$, the bank's ending profit continues to increase as the pledge rate increases, reaching a maximum at 0.673 .

$(0.673 \leq \omega \leq 1$, The bank's ending profit decreases as the pledge rate increases.)

Table 3. The trend of profit and IoT coverage rate when banks adopt IoT technology

\begin{tabular}{|c|c|c|c|c|c|}
\hline$\theta$ & 0.082 & 0.309 & 0.619 & 0.812 & $0.935\}$ \\
\hline$\pi_{2}$ & 11958.9 & 11523.4 & 10363.7 & 9148.0 & 7128.9 \\
\hline
\end{tabular}

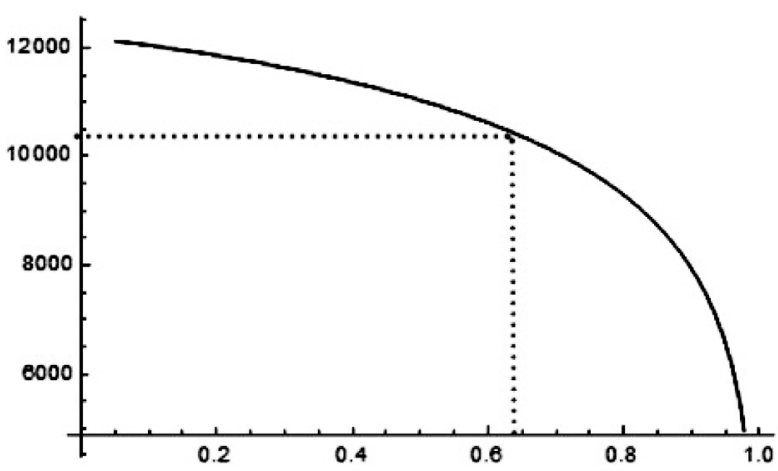

Figure 3. The profit trend of banks under the supervision of the IOT technology

The profit trend of the bank after adopting the Internet of Things technology is shown in Figure 3. According to the simulation results in Table 3, after the bank adopts the IOT technology, as the coverage rate of the IOT increases, the bank's end-of-term profit decreases. Moreover, the rate of decline in bank profits at the end of the period has accelerated, which shows that as the coverage rate of the Internet of Things technology increases after the adoption of the IOT, the marginal cost that the bank needs to pay increases. The higher the coverage rate, the smaller the income from the same level of input; The construction of networking technology requires investment in infrastructure costs. If the coverage is too low, banks are undesirable and can therefore be ignored. The cost of realizing full coverage is infinite, so the coverage rate cannot reach 1 . The final comparison of the numerical simulation results of the two models shows that when the Internet of Things technology coverage rate is within the range of $(0,0.619)$ 
The profit obtained by using IoT technology to supervise pledges is higher than the profit obtained by not using IoT technology. At this time, IoT technology can be adopted. If the coverage rate exceeds 0.619 , the bank's income from using IoT technology supervision is lower than if it is not adopted. Therefore, it is not suitable for the adoption of IOT technology.

\section{Conclusion}

Based on the consideration of the loss of pledges, this paper studies the pledge rate decision-making under the supervision of the bank's use and non-use of Internet of Things technology to supervise the pledges of the inventory pledge business, establishes the decision model in two cases, and analyzes the calculation examples . Research shows that when banks do not use Internet of Things technology to monitor pledges, there is an optimal pledge rate and optimal end-of-period return. After adopting Internet of Things technology, banks can only reduce pledges through supervision if the coverage rate is within a certain range. Attrition rate, so that the profit at the end of the period exceeds the profit at the end of the period without the use of IoT technology supervision. The research in this paper provides guidance for the decision-making of the pledge rate of the bank's inventory pledge business and provides a basis for whether to adopt the Internet of Things technology to strengthen supervision under the new situation.

\section{References}

[1] 2020 China's small and medium-sized enterprise market status survey and development trend forecast analysis report. https://www.cir.cn/R_JinRongTouZi/08/ZhongXiaoQiYeDeFaZhanQuShi.html

[2] Gengzhong Feng.Analysis of Logistics Financing Business Innovation in China $[\mathrm{J}]$. Forecasting, 2007(01):49-54.

[3] Yixue Li, Gengzhong Feng, Yu Xu. Research On Loan-to-value Ratio of Inventory Financing under Randomly-fluctuant Price[J]. Systems Engineering-Theory \& Practice,2007(12):42-48.

[4] Poe T R.Subjective judgments and the asset-based lender[J].Commercial lending Review,1998,13(2):67-70.
[5] Wright JF. Accounting:Inventory-based lending[J]. Commercial Lending Review,1988, (3): 97-99.

[6] Yixue Li, Yu Xu, Gengzhong Feng. Research on the evolution process of inventory pledge financing business at home and abroad [J]. Research on Economics and Management, 2007,(3):22-26

[7] Cossin D,Huang Z,Aunon-Nerin D,et al.A Framework for Collateral Risk Control Determination[J]. Fame Research Paper, 2002.

[8] Yixue Li, Yu Xu, Gengzhong Feng On Loan-to-Value Ratios of Inventory Financing with Doubly Stochastic Poisson Default Processes [J]. Chinese Journal of Management Science,2007(01):21-26.

[9] Hui Yu,Xueping Zhen. Loan-to-Value Ratios Model of Pledge by Warehouse Receipts for Small and Medium Enterprises [J]. Chinese Journal of Management Science,2010,18(06):104-112.

[10] Qinhong Zhang,Quanwu Zhao. Research on Loan-tovalue Ratio of Inventory Financing When Demand Is Stochastic [J]. Chinese Journal of Management Science,2010,18(05):21-27.

[11] Yan Shi,Fangming Zhou. A Production-inventory Model for Perishable Goods with Inventory Impawn Financing Strategy [J]. Jiangxi Science,2014,32(03):385-389.

[12] Yongming Pan,Feng Ni. Research on the Financing Decision of Bank inventory pledge considering material loss [J]. Operations Research and Management Science,2015,24(06):233-241.

[13] Yunfeng Zhang,Yong Wang,Bengang Gong. Research on Contract Design for Inventory Financing Considering the Loss of Pledged Goods [J]. Operations Research and Management Science,2017,26(11):145-153.

[14] Yunfeng Zhang, Bengang Gong,Yunmiao Du. Decision-models of Inventory Financing for Loss of Goods Considering Investment Demand [J]. Operations Research and Management Science,2020,29(06):179-186.

[15] Yongzhang Gong,Feng Liu,Ruiqi Pang, et al, Supervision of Supply Chain Logistics Finance Based on the Internet of Things $[\mathrm{J}]$. Forum on Science and Technology in China,2017(6): 131-136.

[16] Lingyan Jiang,Xiaoguang Wang. Risk Prevention of Repetitive Pledge Under Internet of Things [J]. Computer Engineering and Applications, 2019,55(09):223-229. 